\title{
Letters
}

Website: bmj.com

Email: letters@bmj.com

\section{VAT and fat}

\section{Will sales tax influence consumption?}

EDITOR-Marshall has produced an original but flawed article, opening debate on public and preventive health by arguing that serum cholesterol concentrations are closely related to diet and to ischaemic heart disease; that dairy produce, pastries, and puddings account for more than $40 \%$ of the saturated fat in the British diet; and that introducing value added tax (VAT) at 17.5\% on these foodstuffs, but leaving foods such as semi-skimmed milk and low fat margarine VAT free, could, because of "price elasticity" in demand, save 900 lives a year. ${ }^{1}$

This raises the question, why do we have sales taxes? Assuming that your country isn't engaged in protectionism, there are two reasons: to raise revenue and to influence demand towards more desirable commodities-for example, lower taxes on unleaded petrol. Taxes on tobacco and alcohol have been largely in the first category (the puritanical element in British society no doubt delighted in the added expense of such sinful pleasures). But they are moving, especially taxes on tobacco, towards the second category. VAT is not paid on most foodstuffs, although it is paid on luxury items.

\section{Advice to authors}

We prefer to receive all responses electronically, sent either directly to our website or to the editorial office as email or on a disk. Processing your letter will be delayed unless it arrives in an electronic form.

We are now posting all direct submissions to our website within 24 hours of receipt and our intention is to post all other electronic submissions there as well. All responses will be eligible for publication in the paper journal.

Responses should be under 400 words and relate to articles published in the preceding month. They should include $\leqslant 5$ references, in the Vancouver style, including one to the BMJ article to which they relate. We welcome illustrations.

Please supply each author's current appointment and full address, and a phone or fax number or email address for the corresponding author. We ask authors to declare any competing interest. Please send a stamped addressed envelope if you would like to know whether your letter has been accepted or rejected.

Letters will be edited and may be shortened.

bmj.com

letters@bmj.com
But Marshall proposes making foods that damage health liable to VAT as well.

Three issues arise:

- Equity: although Marshall acknowledges that such taxes are regressive-that is, they fall most heavily on poor people-he shoots himself in the foot by proposing to compensate poorer people by diverting the extra VAT into higher benefits. Such "hypothecated taxation" is not popular, and with their spending power restored poor people will buy exactly the same foodstuffs. Also, although this system compensates those people on welfare, it does little for those people who are employed on low wages.

- Practicality: the wealthier, and healthier, have already ceased smoking, changed their diet, and joined gyms. These people with high living standards have clear interests in maintaining health to enjoy their status, and they also feel that their own actions influence their lives. In comparison, the poor often feel disempowered, and they may be so stressed about making ends meet that their future health is not on the list of things to worry about. For various reasons, those foods rich in saturated fat offer compensations in a bleak world. Such financial manipulations, especially if "compensated," seem unlikely to alter consumption. Despite rising tobacco taxes, smoking is more prevalent among those who are less affluent.

- Effect on mortality and morbidity: ischaemic heart disease is multifactorial in its aetiology, and it seems dangerous to concentrate on single factors.

Alan O'Rourke information officer

Wisdom Centre, Institute of General Practice and Primary Care, Sheffield University Community Sciences Centre, Northern General Hospital, Sheffield S5 7AU

a.j.orourke@sheffield.ac.uk

Competing interests: None declared.

1 Marshall T. Exploring a fiscal food policy: the case of diet and ischaemic heart disease. BMJ 2000;320:301-4. (29 January.)

\section{Taxing single nutrient is dangerous}

EDITOR-The relationship between diet and blood cholesterol concentration is much more complex than Marshall indicates in his recent article. ${ }^{1}$ This complexity has major implications for a fiscal food policy aimed at extending VAT to the major sources of saturated fat in the diet.

Stearic acid is the second most abundant saturated fatty acid and the fourth most abundant fatty acid in the British diet. It has been repeatedly shown that stearic acid is neutral with respect to its effects on the blood cholesterol concentration. This was recognised by Keys et al who, in the paper cited by Marshall, modified the term for saturated fat in his equation to exclude stearic acid. ${ }^{2}$ Marshall used the original equation, not the modified one. Clarke et al (cited by Marshall) recently concluded that stearic acid "did not seem to be significantly related to blood cholesterol concentration."

Other factors complicate the relationship between dietary fat and blood cholesterol concentration. Saturated fatty acids with fewer than 12 carbon atoms also have no effect on the blood cholesterol level. Other classes of fatty acid, notably trans unsaturated fatty acids, raise the blood cholesterol level. What Marshall's approach needs, therefore, is a measure of the fatty acids in a food that raise cholesterol, which is not synonymous with the food's saturated fatty acid content. His approach probably also needs to take into consideration the nature of the carbohydrate and protein in a food, which can also influence the blood cholesterol concentration. These considerations are far from being purely academic. This is well illustrated by the example of whole milk. Marshall identified whole milk as one of the main sources of saturated fat in the diet. The difficulty with his argument is that up to half the saturated fatty acids in milk are neutral with respect to the blood cholesterol concentration. This helps to explain why whole milk lowers the blood cholesterol concentration by $5 \%{ }^{4}$

Foods are complex mixtures of nutrients. Whole milk contains several lipid soluble anticancer agents that are not present in skimmed milk. ${ }^{5}$ In seeking to tax a food to reduce the risk of one disease Marshall may increase the risk of developing another. This illustrates the dangers of taxing a food on the basis of its content of a single nutrient.

John C Stanley consultant in nutrition Lincoln Edge Nutrition, Sleaford Road, Wellingore, Lincoln LN5 0HR

john.stanley@tri.ox.ac.uk

Competing interests: Dr Stanley has received fees for work carried out for the National Dairy Council.

1 Marshall T. Exploring a fiscal food policy: the case of die and ischaemic heart disease. BMJ 2000;320:301-4. (29 January.)

2 Keys A, Anderson JT, Grande F. Serum cholesterol responses to changes in the diet. IV. Particular saturated fats in the diet. Metabolism 1965;14:776-86.

3 Clarke R, Frost C, Collins R, Appleby P, Peto R. Dietary lipids and blood cholesterol: quantitative meta-analysis of metabolic ward studies. BMJ 1997:314:112-7.

4 Howard NA, Marks J. Hypocholesterolaemic effect of milk. Lancet 1977;ii:255-6.

5 Parodi PW. Conjugated linoleic acid and other anticarcinogenic agents of bovine milk fat. J Dairy Sci 1999;82 1339-49. 


\section{Evidence is contradictory}

EDITOR-Marshall's proposal to treat ischaemic heart disease by fiscal measures is based on the assumption that diet determines cholesterol concentrations, which again determine the prevalence of ischaemic heart disease. ${ }^{1}$ These assumptions have been iterated for decades in spite of many contradictory observations and experiments. Let it suffice to mention some of the most salient facts concerning the alleged link between dietary fats and ischaemic heart disease. ${ }^{23}$

Secular trends of national fat consumption and mortality caused by ischaemic heart disease contradict each other almost as often as they coincide. ${ }^{2}$ Among 21 cohort studies of ischaemic heart disease including 28 cohorts and more than 150000 individuals, people who developed ischaemic heart disease ate considerably more saturated fats than those without ischaemic heart disease in three cohorts, and considerably less in one cohort; in 22 cohorts no difference was found. In three cohorts those people who developed ischaemic heart disease had eaten more polyunsaturated fats; in 24 cohorts no difference was recorded. (In a few studies the consumption of saturated or polyunsaturated fats was not recorded.) $)^{2}$

Three of four cohort studies analysed the correlation between the consumption of saturated and polyunsaturated fats and the degree of atherosclerosis at necropsy; none of them found any. All four analysed the total fat intake: in one study it was correlated with degree of atherosclerosis; in another study no correlation was found; and in two studies the correlation was inverse. ${ }^{2}$

In six case-control studies of patients with ischaemic heart disease and of controls matched for sex and age, no important differences were noted between their intakes of saturated or polyunsaturated fats. ${ }^{2}$

In a meta-analysis of nine controlled, randomised, unifactorial, dietary trials with reductions of saturated fats and additions of polyunsaturated fats that were more radical than any of the official recommendations, neither total mortality (odds ratio 0.99 ) nor ischaemic heart disease mortality (odds ratio 0.94 , confidence interval 0.80 to 1.10 ) was lowered; the total number of deaths in the treatment and control groups was identical. ${ }^{2}$

In the only unifactorial, dietary trial that lowered fatal and non-fatal ischaemic heart disease considerably which was included in the mentioned meta-analysis, the cholesterol concentrations in the diet group and the control group were almost identical. ${ }^{4}$

The edible oil industry may applaud the idea of fiscal medicine, but those of us who prefer evidence based medicine will not.

Uffe Ravnskov private practitioner

Råbygatan 2, S-22361 Lund, Sweden

uffe.ravnskov@swipnet.se

Dr Ravnskov was paid by Dairy Farmers of Canada in 1999 for two identical lectures summarising reference 2.

1 Marshall T. Exploring a fiscal food policy: the case of diet and ischaemic heart disease. BMJ 2000;320:301-4. (29 January.)
2 Ravnskov U. The questionable role of saturated and polyunsaturated fatty acids in cardiovascular disease. $J$ Clin Epidemiol 1998;51:443-60.

3 Ravnskov U. The cholesterol myths. http://home2 swipnet.se/ w-25775/ (accessed 26 Apr 2000).

4 De Lorgeril M, Salen P, Martin JL, Monjaud I, Delaye J. Mamelle N. Mediterranean diet, traditional risk factors, and the rate of cardiovascular complications after myocardial infarction. Final report of the Lyon Diet Heart Study. Circulation 1999;99:779-85.

\section{Author's reply}

EDITOR-My article on the use of taxation to influence diet has stimulated considerable discussion. ${ }^{1}$ O'Rourke says that taxation may be intended to raise revenue or to influence demand. Irrespective of intention, all taxation will do both. The magnitude of the price elasticity of demand determines which effect predominates. He also implies that the poor can imagine no better use for additional income than to buy taxed foodstuffs. Economics (household production theory) and common sense indicate otherwise. Housing, clothing, transport, entertainment, and other goods will also make claims on extra money. He suggests that focusing on a single risk factor may be dangerous - an argument that might equally be advanced against quitting smoking.

I agree that a fiscal food policy should be based on a detailed analysis of the net effects of foodstuffs on cholesterol levels.

Ravnskov's views on the irrelevance of cholesterol concentrations to heart disease are at variance with much evidence, including the demonstrated effectiveness of statins. Nevertheless, to avoid the accusation that either of us could be citing evidence selectively, there is a place for a further systematic review to resolve this issue.

Policies to influence food prices are not new. To reduce undernutrition, many developing countries subsidise staple foodstuffs. In my own view there are three arguments against a fiscal food policy: it would not result in dietary change, it would be inequitable, and it would erode our personal freedom. The first argument can be resolved only by the further research that I advocate. Regarding the second: data are available on average weekly expenditures on different foodstuffs. ${ }^{2}$ From these it is possible to estimate the equity effects of a fiscal food policy. On average, individuals could expect to spend an additional $£ 0.30$ a week in tax. The additional $£ 15.2 \mathrm{~m}$ a week raised by this would be sufficient to increase benefits to 10.4 million people on low incomes by $£ 1.30$ a week. They would therefore be better off. All families with children under two years old (for whom full-cream milk is recommended) could also be provided with full-cream milk vouchers worth $£ 1$ a week. This would affect 1.7 million people, and would represent an extra expenditure to the government of $£ 1.7 \mathrm{~m}$. Would such a policy erode our personal freedom? Yes, by $£ 0.30$ a week. Would we each be prepared to forgo $£ 0.30$ a week so that 900 fewer of us die prematurely each year? In the end this is a political choice. But it is only by further investigation that we will be clear what alternatives there really are to choose between.
Tom Marshall clinical lecturer in public health medicine

Department of Public Health and Epidemiology, University of Birmingham, Edgbaston, Birmingham B15 2TT

MarshaTP@hsrc1.bham.ac.uk

Competing interests: None declared.

1 Marshall T. Exploring a fiscal food policy: the case of diet and ischaemic heart disease. BMJ 2000;320:301-4. (29 January.)

2 Ministry of Agriculture, Fisheries, and Food. National food survey 1998. London: Stationery Office, 1999.

\section{The Newcastle exercise project}

\section{Conclusions are misleading}

EDITOR-We welcome the article by Harland et al on promoting physical activity in primary care but dispute the conclusion that these schemes are of questionable effectiveness. ${ }^{1}$ The title for the paragraph for This week in the $B M J$ that "exercise on prescription" is a waste of scarce resources is also misleading and not justified by evidence to date.

Our response stems from concerns about their intervention approach and our experience in two research endeavours: implementing a physical activity prescription scheme in New Zealand and a recently published randomised controlled trial resulting in long term improvement in physical activity for older people. ${ }^{2}$

Firstly, we question whether the level of intervention with the control group (information and recommendations about activity) resulted in a comparison with a lesser intervention, rather than a true control group, perhaps underestimating the efficacy of exercise counselling.

Secondly, is lengthy motivational interviewing appropriate and replicable in a general practice setting? This approach is time intensive for general practitioners and practice nurses and perhaps limits effective long term follow up. In New Zealand $51 \%$ of general practitioners are prescribing physical activity through the Hillary commission's "green prescriptions" scheme. ${ }^{3}$ One of the barriers to exercise prescription is lack of time during the consultation. ${ }^{45}$ We contend that interventions that are quick and simple to implement with regular practice based reinforcement offer more potential for sustainability and long term effectiveness.

Individualised assessment and programme design benefit outcome in health promotion trials. The judgment of the general practitioner is key in this area. The intervention design of a recent successful randomised controlled trial, set in Melbourne, Australia, ${ }^{2}$ raised the consciousness of the general practitioner through an effective educational programme, but it left the details of whom to target and the exact content of advice to the professional judgment of the general practitioners. In Newcastle the general practitioners seemed to be virtual bystanders to the design and delivery of the intervention. We contend that the skills of the general practitioners should play a 
central part in physical activity interventions.

We recognise the need for outcome based evaluations in this area of health promotion. A three year study has begun in New Zealand, which evaluates the long term effectiveness of green prescriptions in increasing physical activity and improving cardiovascular risk index and quality of life of middle aged and older people at risk from physical inactivity, by comparing the intervention with a true control group that receives no advice.

Exercise on prescription a waste of scarce resources? We await the evidence to answer this question.

Ngaire Kerse senior lecturer

Department of General Practice and Primary

Health Care, Auckland, New Zealand

n.kerse@auckland.ac.nz

Sue Walker research and information manager Hillary Commission for Sport Fitness and Leisure, Wellington, New Zealand

Harland J, White M, Drinkwater C, Chinn D, Farr L, Howe D. The Newcastle exercise project: a randomised D. The Newcastle controlled trial of nethods to promote physical activity in primary care. BM 1999, $319.828-32 .(25$ September.)

Kers NM, Joley D, Anst B, Fick D. Improving health behaviours of the elderly: a randomised controlled trial of a general practice educational intervention. BMJ 1999;319:683-7.

3 IMS Health (NZ). Green prescriptions in general practice. Sum mary report, November 1999. Auckland: IMS NZ, 1999 (Available from Intercontinental Medical Statistics, Level 1, ASB Hurstmere Building, 33-45 Hurstmere Road, Takapuna, Auckland, New Zealand.)

4 Swinburn BA, Walter LG, Arroll B, Tilyard MW, Russel DG. Green prescriptions: attitudes and perceptions of general practitioners towards prescribing exercise. $\mathrm{Br} J \mathrm{Gen}$ Pract 1997;47:567-9.

5 Swinburn BA, Walter LG, Arroll B, Tilyard MW, Russel pres advice provided by general practitioners. Am J Public Health 1998;88:288-91.

\section{Jury is still out}

EDITOR-Harland et al have made a valuable contribution to the evidence base that currently underpins the promotion of physical activity. ${ }^{1}$ We are concerned that several features of their study may reduce the external and internal validity of the conclusions that have been reached.

The study described does not examine an exercise on prescription scheme. All patients aged 40-64 attending surgeries were approached and considered. This is, therefore, a population sample, not a targeting of selected patients by a general practitioner. Furthermore, because the response to this initial invitation to participate was low, those who agreed to participate may have been the most enthusiastic and not representative of the general population. This may have reduced both the likelihood of proving the effectiveness of the intervention and the validity of the findings with respect to the general population.

The interventions that were evaluated were very intensive and are unlikely to be feasible in an average primary care setting. In addition, whereas the specific method of promoting physical activity is undoubtedly an important issue, it does not stand alone. It is also necessary to consider broader social factors that may mask the effect of an intervention at this level. These would include the availability of time to attend and the accessibility of facilities.

The authors have based sample size calculations on the number of participants that would be required to detect a difference between success rates of 40-60\%. In addition to the fact that the required number of participants was not met, the prospect of achieving such a large difference in success rates seems rather ambitious.

Although we agree with the authors' conclusion that further research is necessary to develop interventions that promote long term adherence to exercise, it is important that the exercise on prescription scheme is differentiated from population strategies that attempt to raise the level of exercise generally.

Marko Petrovic specialist registrar in public health medicine

marko.petrovic@nwales-ha.wales.nhs.uk

Jeremy Corson deputy director of public health Lyndon Miles specialist registrar in public health medicine

Elwyn Williams health promotion manager,

department of public health

North Wales Health Authority, Preswylfa, Mold,

Flintshire CH7 1PZ

Hilary Fielder clinical senior lecturer in

envirommental epidemiology

Department of Epidemiology and Public Health, University of Wales College of Medicine, Heath Park, Cardiff CF14 4XN

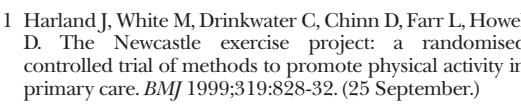

1 Harland J, White M, Drinkwater C, Chinn D, Farr L, Howe D. The Newcastle exercise project: a randomise controlled trial of methods to promote physical activity in primary care. BMJ 1999;319:828-32. (25 September.)

\section{Headline for This week in the BMJ is misleading}

EDITOR-We would like to take issue with the title of the paragraph for This week in the $B M J$, "Exercise on prescription' is a waste of scarce resources," for Harland et al's article on physical activity. The article showed that all four intervention groups showed a significant increase in self reported activity at 12 weeks, compared with a control group that increased reported activity in $16 \%$. In addition there was a suggestion of a dose-response effect as the greatest increase was seen in the group with financial inducement and multiple interventions. It was a pity that Harland et al did not report on the physiological and exercise test outcomes in this paper.

The control group had in effect a brief intervention akin to an exercise prevention. This trial produced no evidence that more intense intervention in the short term produces sustained effects, as reflected by the findings at one year. This is not surprising given the trial design. Numerous other studies $^{2-4}$ show that frequent contact with the subjects, even by brief telephone calls, limits dropouts and that perhaps at least six months of professional contact is needed before the increased physical activity pattern becomes incorporated into behaviour. The key seems to be not so much intensity of contact but continuity over time. Such continuity is a feature of general practice; this should remain an arena for testing such interventions.
Harland's trial shows that in general practice in the United Kingdom patients may be recruited from a comparatively deprived inner city area, and their physical behaviour can be increased by intervention from a researcher, mirroring encouraging trials with primary care doctors from the rest of the world. ${ }^{5}$ What they have not shown is how to maintain the increased activity. This requires further studies, and we believe that the headline is misleading and discouraging to researchers and funding authorities.

Frank Smith director of postgraduate general practice education

NHS Executive, Wessex Deanery, Highcroft,

Winchester SO22 5DH

Fsmith@doh.gov.uk

Jane Sims senior lecturer

Department of General Practice and Public Health, University of Melbourne, 3182 Victoria, Australia j.sims@gpph.unimelb.edu.au

1 Harland J, White M, Drinkwater C, Chinn D, Farr L, Howe D. The Newcastle exercise project: a randomised controlled trial of methods to promote physical activity in primary care. BMJ 1999;319:828-32. (25 September.)

2 Murdo ME, Burnett L. Randomised controlled trial of exercise in the elderly. Gerontol 1992;36:292-8.

3 Hamdorf PA, Withers RT, Penhall RK, Plummer JL. A follow up study on the effects of training on the fitness and habitual activity patterns of 60-70 year old women. Arch Phys Med Rehab 1993;74:473-7.

4 King A, Haskell W, Taylor C, Kraemer H, DeBusk R. Group- vs home-based exercise training in healthy older men and women. A community based clinical trial. JAMA 1991:266:1535-42.

5 Swinburn BA, Walter LG, Arroll B, Tilyard MW, Russell

DG. The green prescription study: a randomized DG. The green prescription study: a randomized
controlled trial of written exercise advice provided by general practitioners. Am J Public Health 1998;88:288-91.

\section{Key messages are misleading and} conclusions are not evidence based

EDITOR-We welcome the addition of this study to the debate on the efficacy of exercise referral, but we believe that Harland et al have asked the wrong questions and therefore drawn the wrong conclusions.

Harland et al wanted to know whether there was a difference between the various interventions and control in changes in physical activity score from 12 weeks to one year. Since there were no differences, the headline for This week in the $B M J$ stated that prescription of exercise is a waste of scarce resources. A better question would be to ask whether any group had increased their activity at one year compared with baseline. According to the data Harland et al present in table 2, the percentage of participants who had increased physical activity scores at one year compared with baseline ranged from $23 \%$ in the control group to $31 \%$ in intervention 3. If these are significant changes from baseline then the conclusion might have been that even the control condition can have a substantial impact in increasing physical activity over one year. Further economic analysis might then determine that the control (which seemed to include the basis of many intervention techniques such as assessment, feedback, and the provision of information) was the most cost effective intervention. The authors' conclusion that brief interventions are of questionable effectiveness is wrong since none of their interventions or even the control 
condition could be described as brief. In our own research we have shown that much briefer interventions (provision of an information booklet alone) can still increase physical activity up to six months. ${ }^{2}$

The outcome measures also asked the wrong questions since they were based on an outdated questionnaire. A better option would have been to determine whether participants had achieved the current targets for sedentary individuals of accumulating 30 minutes of moderate activity on most days of the week. ${ }^{3}{ }^{4}$

The authors claim that the research is based on the stage of change model. However, they have not reported how interventions were tailored to stages, any details of pre-intervention or post-intervention stages, the effectiveness of interventions by stage, or the other crucial elements of this model such as the processes of change and self efficacy measures. ${ }^{5}$

These flaws mean that the key messages are misleading and that the conclusions drawn are not evidence based. Such misinterpretation could severely limit future research and service developments.

Nanette Mutrie senior lecturer

n.mutrie@bio.gla.ac.uk

Catherine Woods researcher

Mathew Lowther researcher

Centre for Exercise Science and Medicine,

University of Glasgow, Glasgow G12 8LT

Avril Blamey health promotion programmes manager Greater Glasgow Health Board, Glasgow G3 8YY

Christopher Loughlan research and development and teaching manager

Addenbrooke's Hospital, Cambridge CB2 2QQ

1 Harland J, White M, Drinkwater C, Chinn D, Farr L, Howe D. The Newcastle exercise project: a randomised controlled trial of methods to promote physical activity in primary care. $B M J$ I 1999;319:828-32. (25 September)

2 Loughlan C, Mutrie N. An evaluation of the effectiveness of three interventions in promoting physical activity in a of three interventions in promoting physical activity

3 Scottish Office. Towards a healthier Scotland-a white paper on health. Edino. Towards a healthier Scotlan

4 hate RR, Pratt M, Blair SN, Haskell WL, Macera CA, Bouchard C, et al. Physical activity and public health: a chard $\mathrm{C}$, et al. Physical activity and public health: a
recommendation from the Centers for Disease Control recommendation from the Centers for Disease Control
and Prevention and the American College of Sports Medicine. JAMA 1995;273:402-7.

5 Marcus BH, Eaton, CA Rossi JS, Harlow LL. Self-efficacy, decision-making, and stages of change: an integrative model of physical exercise. J Appl Soc Psychol 1994;24: $489-508$

\section{Organisational aspects may influence adherence rates}

EdiTor-Harland et al report on a randomised controlled trial of methods to promote physical activity in primary care. ${ }^{1}$ The most intensive intervention was not effective in increasing physical activity at one year follow up, which highlights the need to develop interventions that promote long term adherence.

A further randomised controlled trial of a referral programme for physical activity in primary care is currently under way in Barnet (EXERT study). Participants are randomised to one of three treatment arms: tailored advice (control group), leisure centre based exercise classes, and a more community based walking programme. Patients aged 40-74 with at least one cardiovascular risk factor are eligible for inclusion. Cur-
Comparison of uptake of classes in Newcastle and EXERT study

\begin{tabular}{lcc} 
& Newcastle & EXERT \\
\hline $\begin{array}{l}\text { Proportion of patients attending at } \\
\text { least one session }\end{array}$ & 0.41 & 0.86 \\
\hline $\begin{array}{l}\text { Proportion of all available sessions } \\
\text { attended }\end{array}$ & 0.12 & 0.50 \\
\hline $\begin{array}{l}\text { Mean No of sessions attended per } \\
\text { week }^{*}\end{array}$ & 0.78 & 1.26 \\
\hline
\end{tabular}

${ }^{\star}$ By those attending at least one session.

rently 600 have been randomised; we expect to recruit over 1000. All recruits receive a detailed assessment before randomisation, including measurement of blood pressure blood lipid concentrations, anthropometric variables, cardiovascular fitness, psychological status, and quality of life. Follow up with similar tests is carried out at the end of the exercise programme, after six months, and at one year.

The Barnet programme differs from the Newcastle trial in several organisational aspects that may influence longer term adherence rates. Both intervention arms are run as a series of cohorts, with participants starting and finishing the 10 week programme at the same time. They are also led by instructors and designed specifically for the patient population. Hence, the extent of motivation and support offered is much higher; participants can potentially see the same instructor several times a week. Participants report enjoying the social element of the programme, particularly the fact that classes contain only referrals from general practitioners. A lack of designated classes may explain the low uptake of vouchers in the Newcastle scheme, compared with a higher participation in EXERT (table).

A further methodological issue discussed is the possible motivational effect on controls of a baseline assessment. The EXERT study will allow evaluation of the effect of a "fitness test," as $50 \%$ of participants from each arm are randomised to receive this at 10 weeks, while the remainder have no additional measurements between baseline and six months.

This design offers an alternative model for promoting physical activity. The study will have included sufficient numbers of patients to enable an interim report on adherence for comparison with the results of the Newcastle study later this year.

Julia Critchley research officer

Julia.Critchley@barnet-ha.nthames.nhs.uk

Anthony J Isaacs consultant, public health department Rochelle Rosenthall research nurse

Barnet Health Authority, London NW9 6QQ

Lorraine Honeybell fitness instructor

Chris Smith fitness instructor

London Borough of Barnet, Barnet Copthall

Centre, London NW4 1PS

The EXERT study is funded by the NHS Health Technology Assessment Programme.

\footnotetext{
1 Harland J, White M, Drinkwater C, Chinn D, Farr R, Howel D. The Newcastle exercise project: a randomised controlled trial of methods to promote physical activity in primary care. BMJ 1999:319:828-32. (25 September.)
}

\section{Group support is crucial to success}

EDIToR-I applaud Hartland et al for attempting to appraise the efficacy of exercise prescription by general practitioners. ${ }^{1}$ The programme they studied in Newcastle is, however, unlikely to achieve long term changes in lifestyle because it is flawed. Compliance will be achieved only if participants go through their exercise programme in mutually supportive groups.

A scheme in mid-Devon in which participants felt part of a group of about 15 has been popular and successful. In 1994 a health prescription scheme was started in Cullompton, a market town in Devon with a population of about 6000. Altogether 33 general practitioners with a total of 47855 patients on their lists were invited to participate in the scheme, and 474 patients were referred to the Culm Valley Sports Centre in a 12 month period in 1995-6 for the following reasons in rank order: general unfitness, overweight, depression or fatigue, back pain, heart surgery, injury, arthritis or immobility, hypertension, neurological problems, and diabetes. The programme was set up by a physiotherapist and an exercise trainer, who was dedicated full time to the scheme.

Funds for additional equipment were provided by Mid-Devon District Council. Participants paid reduced charges $(£ 1.95$ instead of £2.60) and in groups of about 10 attended twice a week for 10 weeks at off-peak times. They had a free initial assessment (usual cost $£ 9$ ), which included measurement of blood pressure, pulse rate before and after exercise, body dimensions, fat thickness, and peak flow. Despite the reduction in charges the scheme has been self funding.

Fox et al studied exercise prescription schemes and included the following among the advantages ${ }^{2}$ :

- Ease with which general practitioners can contribute

- Willingness of leisure centre to take on responsibility

- Availability of expertise and facilities

- Popularity among patients

- Motivational effect of group exercise

- Financial viability.

The mid-Devon scheme corroborates these. Functional and psychological benefits were seen in patients with chronic back pain assessed by using a visual analogue scale, the Oswestry low back disability questionnaire, and the hospital anxiety and depression scale. Delays are minimal, which is an obvious benefit when deconditioning is taking place. At times there may be positive advantages in removing some people from the medical arena. The motivational effect of cohesive and mutually supportive groups is crucial to the success of exercise prescription schemes.

Peter J S Baker general practitioner

Exeter EX1 1SE

peterjsbaker@netscapeonline.co.uk

1 Harland J, White M, Drinkwater C, Chinn D, Farr L, Howe D. The Newcastle exercise project: a randomised controlled trial of methods to promote physical activity in primary care $B M$ J 1999: 7213:828-32. (25 September)

2 Fox K Biddle S. Edmunds I Bow ox activity promotion through primary care in England. Br J
Gen Pract 1997:47,367-9. 
Excluded patients should be encouraged to take up exercise

EDITOR-Harland et al report on an attempt to promote physical activity in one general practice. ${ }^{1}$ Their choice of sessions of vigorous activity as part of their main outcome measure was a surprising perpetuation of a common misconception.

It has been clear for some time that regular physical activity at moderate (rather than vigorous) intensity provides substantial health benefits and that activity at low to moderate intensity is more likely to be continued than activity at high intensity. ${ }^{23}$ In addition, levels of habitual physical activity in the general population are so low that to most people the prospect of vigorous activity is a big turnoff. Given that the health benefits gained from increased activity depend on the initial level of activity, a more valuable approach would have been to focus on the number of subjects achieving the transition from sedentary state to regular physical activity at moderate intensity.

We accept that the entry criteria to a research project may not always reflect practice in the real world, but the fact that Harland et al excluded one third of patients from participation on health grounds seems like another lost opportunity. Most adults do not need to see their doctor before starting a programme of physical activity at moderate intensity. ${ }^{4}$ Those subjects excluded by Harland et al because of acute myocardial infarction within the previous 12 months, angina, and cerebrovascular disease are precisely the group that should be receiving strong positive encouragement from their doctors to be regularly physically active.

Marion McMurdo professor of ageing and health Department of Medicine, Ninewells Hospital and Medical School, Dundee DD1 9SY m.e.t.mcmurdo@dundee.ac.uk

Professor McMurdo is codirector of D D Developments, a University of Dundee company whose mission is to provide exercise classes for older people and whose profits support research into ageing and health.

1 Harland J, White M, Drinkwater C, Chinn D, Farr L, Howel D. The Newcastle exercise project: a randomised controlled trial of methods to promote physical activity in primary care. BMJ 1999;319:828-32. (25 September.)

2 Physical Activity and Public Health. A recommendation from the Centers for Disease Control and Prevention and the American College of Sports Medicine JAMA 1995;273:402-7

3 Pollock ML. Prescribing exercise for fitness adherence. In: Dishman RK, ed. Exercise adherence. Champaign, IL: Human Kinetics Publishers, 1988:259-77.

4 American College of Sports Medicine. Guidelines for exercise testing and prescription. 4th ed. Philadelphia, PA: Lea and Febiger; 1991 .

5 Wannamethee G, Shaper AG. Physical activity and stroke in middle aged British men. BMJ 1992;304:597-601

\section{Different exercise prescription schemes} deserve evaluation in United Kingdom

EDITOR-Harland et al ably highlight the shortcomings of exercise prescriptions as a means of promoting physical activity as used in the United Kingdom. ${ }^{1}$ The long term adherence of patients who have been prescribed leisure centre type referrals in their study, even in the group with the most intensive intervention coupled with financial incentive, as in other studies ${ }^{2}$ is disappointingly low. It mirrors exactly our experience with our own scheme. The proliferation of such schemes surely results from a combination of good intentions, ease of setting up, and most particularly cost neutrality to the scarce resources of the NHS.

Well documented exercise prescription schemes of a different type being practised in Europe and the United States, often home based, informal, and unsupervised with limited intervention, nevertheless yield good long term outcomes and rates of adherence. ${ }^{3}$ There may subtle cultural reasons why such practice may not easily transfer to the United Kingdom. Yet, given the well established health and social benefits associated with increased physical activity these types of schemes deserve evaluation here before the prescription of exercise is labelled ineffective.

Mark Reeves general practitioner

Trescobeas Surgery, Falmouth, Cornwall TR11 2UN mark@Holyrood43.demon.co.uk

1 Harland J, White M, Drinkwater C, Chinn D, Farr L, Howe D. The Newcastle exercise project: a randomised controlled trial of methods to promote physical activity in primary care. BMJ 1999;319:828-32. (25 September.)

2 Taylor AH. Evaluating GP exercise referral schemes: finding. from a randomised control study. Eastbourne: University of Brighton, 1996

3 Hillsdon M, Thorogood M, Antiss T, Morris J. Randomised controlled trials of physical activity promotion in fre living populations: a review. J Epidemiol Community Healt 1995:49:448-53.

\section{Authors' reply}

EDITOR-The responses to our paper raise important issues requiring clarification. It was necessary to restrict the outcomes reported in the first paper on this study; other outcomes will be reported separately. Some misconceptions arose because we could not describe the intervention in detail in the space allowed. Our scheme was not an exercise prescription scheme.

The motivational interviews aimed to increase inherent motivation for physical activity rather than prescribing specific activities. Participants were encouraged to tailor their activities to suit their personal circumstances: these varied among facility based lifestyle, solitary, and group activities. The aim was to motivate them to do effective (aerobic) activity at least three times per week for at least 20 minutes per session. Participants were initially encouraged to start any activity and, when ready and if appropriate, to try to increase its frequency and intensity.

The trial was planned as an efficacy (rather than effectiveness) study or evaluation of the experimental stage, with the inherent limitations of such research. ${ }^{2}$ Kerse and Walker and Petrovic et al queried whether our intervention would be feasible and affordable within the resources of the health service. Some misunderstandings may have led correspondents to assume the intervention required more resources than it did. However, refining the intervention so it can be delivered as part of routine primary care is the next logical stage in this programme of research. The results are not generalisable to the population as a whole as mentioned by Petrovic et al, but this was not our aim.

Smith and Sims, Mutrie et al, and Critchley et al commented on the "intervention" received by the control group. We were interested in the effect of motivational interviewing and vouchers over and above the baseline assessment and generally available information so our control group was appropriate for the aims of the trial. Mutrie et al imply that our control group achieved worthwhile increases in physical activity at 12 weeks and one year and suggest that brief interventions may turn out to be the most cost effective way to promote physical activity. This may be so, but our data and those of others show that brief interventions are effective only for a proportion of the population: further attention needs to be paid to the appropriate targeting of brief and more intensive approaches.

We know of no published evidence to support Baker's conjecture that to achieve compliance participants need to go through their exercise programme in mutually supportive groups. This approach is likely to alienate those who are embarrassed at being part of a group, although it may benefit others. Critchley et al suggest an alternative way to address this issue. The nature of our intervention, motivational interview, is, however, quite different from attendance at exercise classes in their study, so the comparison in their table is inappropriate.

Our exclusion criteria reflected the need to exclude patients for whom a submaximal exercise test was unsafe or the results uninterpretable. The exercise test provided physiological measures to validate self reported patterns of activity. In the context of real life, rather than that of an experiment, there would be no need for such a test and no need to exclude such patients.

Mutrie et al state that we used an outdated questionnaire with little known validity to assess physical activity, but that recommended by them was not available at the time of the trial. We accept that questionnaire design has improved since our trial, but the questionnaire we used does not invalidate our results.

Correspondents objected to the headline for This week in the $B M J$. The title was too provocative, and we asked the $B M J$ to modify it before publication, but it was neither totally unjustified nor seriously misleading. Although our trial differs from the popular models of "exercise on prescription" or exercise referral schemes in several ways, the results nevertheless have implications for more typical schemes. Most of these schemes do not address adherence to increased physical activity after the intervention or prescription period (typically 10-12 weeks ${ }^{3}$ ), and few have evaluated long term changes in physical activity. Because they do not address adherence, schemes that promote only adoption of physical activity are, 
in the long term, likely to be ineffective and may be considered a waste of scarce resources. We agree with Smith and Sims on the need for further research on methods to maintain increased activity.

Jane Harland lecturer in primary health care j.o.e.harland@ncl.ac.uk

Martin White senior lecturer in public health Denise Howel senior lecturer in epidemiological statistics

Health Promotion Research Group, School of Health Sciences, University of Newcastle upon Tyne, Newcastle upon Tyne NE2 4HH

Chris Drinkwater professor of primary care development

Primary Care Development Centre, University of Northumbria at Newcastle, Newcastle General Hospital, Newcastle upon Tyne, NE4 6BE

David Chinn senior research fellow in epidemiology Centre for Health and Medical Research, School of Health, University of Teesside, Middlesbrough TS1 3BA

1 Haskell W. Health consequences of physical activity: understanding challenges regarding dose response. Med Sci Sports Exerc 1994;26:649-60.

2 Nutbeam D. Evaluating health promotion-progress, problems and solutions. Health Promotion Int 1998;13(1):27-44 3 Riddoch C, Puig-Ribera A, Cooper A. Effectiveness of physical activity promotion schemes in primary care: a review. London: Health Education Authority, 1998.

\section{National quality assurance framework will guide best value and practice in GP exercise referral schemes}

EDITOR-As authors of a national quality assurance framework for primary care exercise referral systems, we seek to address some of the confusion surrounding the paper by Harland et al. ${ }^{1}$

In 1998 the British Association of Sport and Exercise Science and what was Exercise England were commissioned by the Department of Health to produce a national quality assurance framework for general practitioner exercise referral schemes in the light of extremely varied practice across the United Kingdom. ${ }^{2}$ The national quality assurance framework now awaits its launch (which will be notified to the $B M$ ), subject to clarification of who will be the future custodians of a national register of exercise professionals. To ensure best practice and value the national quality assurance framework adopts a whole systems approach in which clear documentation is produced describing selection criteria, screening and assessment procedures, progression, and the training implications for health and exercise professionals.

The paper by Harland et al illustrates the ambiguity of the term exercise prescription scheme. After much consultation with medicolegal advisers we conclude that general practitioners are rarely in a position to prescribe exercise. Instead, referral schemes should entail extending the primary care service to a qualified exercise leader within a carefully developed service agreement. The exercise referral process in the Newcastle project does not seem to match our guidelines, and exercise referral schemes should not be condemned on the basis of this paper.

We must move forward in the professionalisation of physical activity promotion services linked to primary care, given that physical activity is central to health. ${ }^{3}$ Future research reports on the effectiveness of general practice exercise referral schemes should provide sufficient detail to enable readers to judge the intervention in light of the guidelines of the national quality assurance framework.

Andrew Craig vice chair, Balham, Tooting, and Wandsworth Primary Care Group

Bendon Valley House, London SW18 4EA

Susie Dinan senior exercise practitioner

University Department of Geriatric Medicine, Roval Free Hospital, London NW3 2QG

Andrew Smith chair, British Association of Sport and Exercise Science

College of Ripon and York St John, York YO3 7EX

Adrian Taylor chair, Exercise Science Special

Committee, British Association of Sport and Exercise

Sciences, Leeds

School of PE, Sport, and Leisure, De Montfort

University, Bedford MK40 2BZ

ataylor@dmu.ac.uk

Nick Webborn medical adviser, National Sports

Medicine Institute of the UK

c/o Medical College of St Bartholomew's Hospital, London EC1M 6BQ

1 Harland J, White M, Drinkwater C, Chinn D, Farr L, Howe D. The Newcastle exercise project: a randomised controlled trial of methods to promote physical activity in primary care. BMJ 1999;319:828-32. (25 September.)

2 Riddoch C, Puig-Ribera A, Cooper A. Effectiveness of physical activity promotion schemes in primary care: a review. London: Health Education Authority, 1998.

3 Taylor AH. Exercise promotion in primary health care. In: Bull SJ, ed. Adherence issues in exercise and sport. Chichester Wiley Publishers, 1999:47-74.

\section{Cost utility of drugs for multiple sclerosis}

Systematic review places study in context

EDITOR-We were disappointed that Forbes et al's population based cost utility study of interferon beta- $1 \mathrm{~b}$ in secondary progressive multiple sclerosis was not placed in the context of a systematic review of relevant published work. ${ }^{1}$ We recently completed such a review of the effectiveness, costs, and utility of a range of disease modifying drugs in multiple sclerosis for the health technology assessment programme. As part of this, we searched various electronic databases for published studies of the cost utility of interferon beta in multiple sclerosis: Cochrane Database of Systematic Reviews, Cochrane Controlled Trials Register, Database of Abstracts of Reviews of Effectiveness and NHS Economic Evaluations Database, Medline (Silverplatter), PubMed, Embase, and National Research Register (for the period 1980 to July 1999 and limited to English language studies). In addition, we contacted experts in the field.

In addition to Forbes et al's study, we identified three further studies: one of beta interferons (1a and $1 \mathrm{~b}$ ) in both relapsingremitting and secondary progressive sclerosis $^{2}$ and two further studies of interferon in relapsing-remitting multiple sclerosis. ${ }^{34}$

The table shows a summary of the results of the review. The studies in secondary progressive multiple sclerosis are based on the same trial $(n=718)$ but use different cost utility methodologies. Forbes et al's conclusion that the cost per quality adjusted life year (QALY) was very high (£1 024 667) owing to the high drug cost and modest clinical effect concurs with the previous study's estimate of $£ 874600$ per QALY. The studies in relapsing-remitting multiple sclerosis also use the results of the existing randomised controlled trials in conjunction with various sources of cost data, quality of life measures, and different degrees of decision analytic modelling. Results show that the cost per QALY per relapse avoided is high in all studies.

These cost utility studies were critically appraised by using standard criteria for decision analysis and economic evaluations. Although all used explicit and sensible processes to identify, select, and combine the evidence into probabilities, and to obtain utilities and costs, with uncertainties being addressed by sensitivity analyses, none of them provide a full economic comparison of all possible healthcare strategies. The conclusion of Forbes et al that "far more benefit would be obtained from directing funds into improved supportive care," though plausible, is not supported by the evidence presented. Further economic evaluations of a wider range of possible interventions, such as improved supportive care, are needed so that limited resources can be used effectively.

Jackie Bryant research fellow

Andrew Clegg senior research fellow

Ruairidh Milne senior lecturer in public health

medicine

Wessex Institute for Health Research and

Development, University of Southampton,

Southampton SO16 7PX

Competing interests: None declared.

1 Forbes RB, Lees A, Waugh N, Swingler RJ. Population based cost utility study of interferon beta- $1 \mathrm{~b}$ in secondary progressive multiple sclerosis. BMJ 1999;319:1529-33. (11 December.)

2 Nicolson T, Milne R. Beta interferons (1a and 1 b) in relapsingremitting and secondary progressive multiple sclerosis. South-

Cost per quality adjusted life year of interferons in multiple sclerosis

\begin{tabular}{lllc} 
First author (year) & Country & Drug and patient group & Cost per QALY \\
\hline Forbes $(1999)^{1}$ & United Kingdom & $\begin{array}{l}\text { Interferon beta-1b in secondary } \\
\text { progressive multiple sclerosis }\end{array}$ & $£ 1024000$ \\
\hline Nicholson (1999) & United Kingdom & $\begin{array}{l}\text { Interferon beta-1b in secondary } \\
\text { progressive multiple sclerosis }\end{array}$ & $£ 874600$ \\
\hline Parkin (1998) & United Kingdom & $\begin{array}{l}\text { Interferon beta-1b in } \\
\text { relapsing-remitting multiple sclerosis }\end{array}$ & $£ 809000$ \\
\hline Nicholson (1999) & United Kingdom & $\begin{array}{l}\text { Interferon beta-1a in } \\
\text { relapsing-remitting multiple sclerosis }\end{array}$ & $£ 2038400$ \\
\hline Otten $(1998)^{4}$ & Canada & $\begin{array}{l}\text { Interferon beta-1a in } \\
\text { relapsing-remitting multiple sclerosis }\end{array}$ & $\$ 406000-\$ 490000$ \\
\hline
\end{tabular}


ampton: Wessex Institute for Health Research and Development, 1999. (Development and Evaluation Committee Report No 98.)

3 Parkin D, McNamee P, Jacoby A, Miller P, Thomas S, Bates D. A cost-utility analysis of interferon beta for multiple sclerosis. Health Technol Assess 1998;2(4).

4 Otten N. Comparison of drug treatments for multiple sclerosis Ottawa: Canadian Coordinating Office for Health Technology Assessment, 1998

\section{Methods used don't calculate true benefit}

EDITOR-We would like to draw attention to methodological issues in calculating cost effectiveness in the study by Forbes et al. ${ }^{1}$ They have used the only trial data available, curtailed at 36 months. ${ }^{2}$ For the outcome they used, time to wheelchair dependence, the median point was not reached. Instead, the trial reports, rather vaguely, that the benefit was "a delay of up to 9 months" in time to wheelchair dependence. ${ }^{2}$ This seems to be based on the 83rd centile: at 30 months for the treatment arm and 20.5 months for the control arm (see figure); as such it is an arbitrary measure of the difference between the distribution curves, determined by the length of the trial. As a second dimension of the effectiveness, Forbes et al use the number needed to treat at 30 months (18), based on the relative risk reduction from the trial and the (lower) rate of reaching wheelchair dependency from their Tayside cohort. This gives an average delay for a patient of just 0.5 months for the Tayside patients $(0.9$ months for the trial cohort, ${ }^{2}$ with a number needed to treat of 10 calculated, using the figure below, from the difference between the numbers of treated and control patients at 30 months $(100 / 83-73))$.

The figure plots the estimated probabilities of not being wheelchair dependent from the trial data, ${ }^{2}$ as applied to a cohort of 100 patients. The area under each curve was estimated by summing the areas of the polygons for each month, using a spreadsheet. The difference between them is the difference in the time spent in a wheelchair, and generates a true mean at 30 months of 1.7 months' delay (compared with the 0.9 months above). The method used by Forbes et al estimates only the (marginal) benefit, as represented by the area between the curves from 21 to 30 months.

We believe that this method of the area under the curve offers the best means of cal-

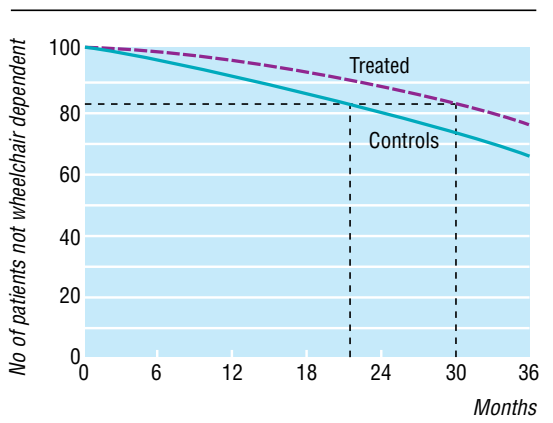

Survival curve to wheelchair dependence in patients with multiple sclerosis treated with interferon beta-1b and controls. Area between curves/ $100=$ average delay; dotted lines indicate 83 rd centile culating true benefit in most cases, especially when data are limited, though it has its own problems. Further debate is needed as methodologies for health economic assessments develop.

As for individual patients, they may be led to believe that treatment with interferon beta- $1 \mathrm{~b}$ offers a nine month delay in becoming wheelchair dependent, whereas in reality it is just 1.7 months on average. Would this knowledge change their perspective?

Richard Richards consultant public health physician North Nottinghamshire Health Authority,

Rainworth, Mansfield NG21 0ER

r.g.richards@shef.ac.uk

Amanda Burls senior clinical lecturer in public health and epidemiology

Department of Public Health and Epidemiology,

University of Birmingham, Edgbaston, Birmingham B15 2TT

Nick Payne clinical senior lecturer

School of Health and Related Research, University of Sheffield, Sheffield S1 4DA

Competing interests: None declared.

1 Forbes RB, Lees A, Waugh N, Swingler RJ. Population based cost utility study of interferon beta-1b in secondar progressive multiple sclerosis. BMJ 1999;319:1529-33. (11 December.)

2 European Study Group on Interferon beta-1b in Secondary Progressive Multiple Sclerosis. Placebo-controlled multicentre randomised trial of interferon beta- $1 \mathrm{~b}$ in treatment secondary progressive multiple sclerosis. Lancel $1998 ; 352: 1491-7$

\section{Analysis goes too far}

EDIToR-The paper by Forbes et al gives the appearance of applying scientific methodology to the challenge of resource allocation. ${ }^{1}$ However, if the methodology is flawed such papers have the potential of influencing the political debate, resulting in patients being deprived of useful treatment.

The paper takes a local audit of people with multiple sclerosis, applies the results from one double blind placebo controlled trial, using a single aspect of disability (wheelchair dependence) and then extrapolates quality adjusted life years (QALYs) to which a price tag is attached. ${ }^{2}$ This results in the apparently exorbitant cost per QALY of $£ 832399$.

The study of the use of interferon beta- $1 \mathrm{~b}$ cited by Forbes et al was designed as an efficacy study. Any further analysis of the data has to be viewed as hypothesis generating rather than as strong evidence in its own right. Post hoc manipulations of data are notoriously unreliable, as was shown by the unfortunate safety scare over the use of selegiline in Parkinson's disease, ${ }^{3}$ which has not been confirmed in other studies.

Although wheelchair dependence is an important aspect of disability in multiple sclerosis, it is not the only one. Any study into the overall benefit of a treatment in multiple sclerosis that used only this one aspect of disability would seriously underestimate the problems associated with this disease.

Assessment of the effect of medical interventions is problematic, ${ }^{4}$ and the underlying assumption behind QALYs that seriousness of a disability is a fixed quantity is unlikely to be true. Many healthy people might say they would prefer to be dead rather than live with a severe disability, but if you ask disabled people, they generally prefer to be alive. The severity of a disability depends on one's perspective and is not fixed.

Forbes et al's paper will be used as strong evidence to limit availability of treatment to patients, and it may constitute another example of the misuse of so called evidence based medicine for rationing purposes. ${ }^{5}$ This sort of exploration should be used as hypothesis generating to inform the design of a proper cost benefit trial.

Simon J Ellis consultant neurologist North Staffordshire Royal Infirmary, Keele University, Stoke on Trent ST4 7LN

Competing interests: Dr Ellis is a blinded assessor in a study of interferon beta run by Serono but with no pecuniary advantage. Serono has paid travel and accommodation expenses for attendance at investigators' meetings.

1 Forbes RB, Lees A, Waugh N, Swingler RJ. Population based cost utility study of interferon beta- $1 \mathrm{~b}$ in secondary progressive multiple sclerosis. BMJ 1999;319:1529-33. (11 December.)

2 European Study Group on Interferon beta-1b in Secondary Progressive Multiple Sclerosis. Placebo-controlled multicentre randomised trial of interferon beta- $1 \mathrm{~b}$ in treatment of secondary progressive multiple sclerosis. Lancet 1998;352:1491-7.

3 Ben-Shlomo Y, Churchyard A, Head J, Hurwitz B, Overstall P, Ockelford J, et al. Investigation by Parkinson's Disease Research Group of United Kingdom into excess mortality seen with combined levodopa and selegiline treatment in patients with early mild Parkinson's disease: treatment in patients with early, mild Parkinson's disease: further results of randomised trial and confidential inquiry.
$B M J$ 1998;316:1191-6.

4 Wright JC, Weinstein MS. Gains in life expectancy from medical interventions-standardizing data outcomes. $N$ Engl J Med 1998;339:380-6.

5 Kryger M. Sleep apnoea and the misuse of evidence based medicine. Lancet 1997; 349:803-4.

\section{Authors' reply}

Editor-Despite the published responses we believe that the conclusion of our study is still a robust one: that the opportunity cost of interferon beta for secondary progressive multiple sclerosis is considerable.

Bryant et al emphasise the need to compare our study with other economic evaluations of interferon beta. We had not quoted studies of relapsing-remitting multiple sclerosis as this is considered a separate entity to secondary progressive disease. Comparisons between studies of secondary progressive and relapsing-remitting multiple sclerosis do not add to our analysis, except to emphasise that interferon beta remains an extremely expensive intervention, whatever the disease type. If quality adjusted life years are a generic measure of health benefits, then our conclusion that supportive care might represent better use of funds is likely to be valid, as few healthcare interventions produce health benefits at such a high cost.

According to Richards, we underestimated the benefits of interferon beta. Even taking such an error into account, our final conclusion is not altered, as the cost utility ratio is driven by the high cost of the drug.

In response to Ellis, an economic model which applies observational data to efficacy data from a randomised controlled trial is preferable to conducting trials with eco- 
nomic end points, as economic data gathered in the context of a trial are unlikely to be generalisable outside of trial settings. ${ }^{1}$ There is also the issue of who should conduct (and pay for) such studies. We accept that in the United Kingdom economic analysis is being used to limit access to interferon beta. However, services for people with neurological disorders remain underdeveloped, and, it is well known that the United Kingdom has fewer neurology specialists than comparable developed nations. In multiple sclerosis, it would be a great pity if huge sums of money were devoted to a drug of marginal benefit to a small number of people, when alternative uses of those funds could deliver a high standard of service and care to a much wider group of people. Technological advances inevitably lead to demands for increased healthcare funding. Those who are developing neurology services should either allow unrestricted prescription of new expensive drugs, such as interferon beta, or consider the relative costs and benefits of new technologies, as alternative uses of development funds (such as simple interventions to reduce symptoms) might better serve the patients under our care.

Raeburn B Forbes specialist registrar Department of Neurology, Royal Victoria Hospital, Belfast BT12 6BA

raeburn.forbes@royalhospitals.n-i.nhs.uk

Robert J Swingler consultant neurologis Ninewells Hospital and Medical School, Dundee DD1 9SY

Competing interests: Drs Forbes and Swingler have investigated and evaluated neurologists for a clinical trial of Antegren in multiple sclerosis, sponsored by Athena Neurosciences. Dr Forbes has received funding to attend a conference from Serono. Dr Swingler has received grants from Serono, Schering Healthcare, and Biogen to fund attendance at conferences.

1 Sheldon T. Problems of using modelling in the economic evaluation of health care. Health Econ 1996;5:1-11.

\section{New guidelines for urgent referral of patients with cancer}

\section{Patients will have a dignified end to life}

EDITOR-Any new policy initiative such as the Department of Health's new guidelines for urgent referral of patients with cancer is inevitably accompanied by the views of both iconoclasts and opportunists. Sikora has clearly expressed his view, but I believe he is wrong. ${ }^{1}$

As a general practitioner I am in a different position from Sikora. Patients do not arrive at my surgery with diagnoses and neatly typed referral letters; they arrive with often vague and undifferentiated problems. My task is to identify which patients with, for example, persistent cough warrant an urgent referral or radiography. Tertiary care specialists may often approach lymphadenopathy with biopsy; in general practice we need to adopt a watchful waiting approach
Sikora may be correct in stating that there is no evidence that delay in diagnosis is a large problem in the United Kingdom. However, a lack of evidence is surely an opportunity for further research.

The guidelines are merely an attempt to identify evidence for the diagnosis of cancer that is applicable to primary care populations which have a low prevalence of cancer. As a member of the working group I accept the criticism that in many areas the evidence is inconclusive and consensus approaches have necessarily been adopted. However, a strong element of primary care has been and continues to be incorporated in the final output. Above all, the process of developing guidelines for referring patients with cancer must be seen as dynamic and evolutionary. It is an opportunity for us in primary care to encourage researchers and policy makers to focus on the clinical questions that matter most to us and not necessarily on populist or pharmaceutical priorities.

Correct and targeted referral should reduce patients' anxiety by ensuring that the right patients reach the appropriate specialist rapidly. When patients cannot be cured they and their general practitioner will have time to sort out benefits and develop a plan of shared care with the oncologist or palliative care specialists. It also allows patients to get their life in order. Aside from effects on mortality, I believe that many patients will be given the opportunity to end life in a more dignified fashion as a consequence of more rapid and appropriate referral by their general practitioner.

Nick Summerton general practitioner The Surgery, Winterton, Scunthorpe DN15 1PN N.Summerton@medschool.hull.ac.uk

Competing interest: Dr Summerton is a member of the cancer referral guidelines group.

1 Sikora K. New guidelines for urgent referral of patient with cancer are waste of energy. BMJ 2000;320:59. (1 January.

2 Department of Health. Referral guidelines for suspected cancer-consultation document. London: DoH, 1999. (HSC1999/241.) www.doh.gov.uk/cancer (accessed 1 Apr 2000)

\section{The initiative should not be dismissed}

EDITOR-Sikora criticises the two week waiting initiative for patients with suspected cancer and the referral guidance from the Department of Health, ${ }^{1}$ arguing that these will not improve survival and that money is better spent implementing the CalmanHine recommendations and buying new cancer treatments.

We agree that the Calman-Hine report is only partially implemented, but we suggest a different perspective. Work so far has been the designation of cancer units and centres, although the report also saw primary care as the focus of care, recommended public and professional education to help early recognition, and detailed discussion between primary care, units, and centres to clarify patterns of referral.

Sikora states that delay in diagnosis is not important in the United Kingdom, where a wide range of referral times is evident. For example, studies of colorectal cancer reviewed by the Clinical Outcome Group found median delays ranging from less than 1 month to more than 4 months before referral and 6-7 weeks before diagnosis. ${ }^{4}$ A recent audit in Merton, Sutton, and Wandsworth Health Authority found that such delays could occur and revealed the distress that this caused some patients. It is not "window dressing" to mind about this, nor "an obsession with waiting list targets" to turn attention from routine surgery to the second most common cause of death. Reducing referral times will avoid unnecessary distress for patients, may reduce morbidity, and may even have a small effect on survival.

Sikora describes the guidance as "a reasonable distillation of textbook knowledge" which is "patronising" to well educated doctors. In fact general practitioners worked on most tumour specific subgroups to collate a research and consensus view not found in textbooks. ${ }^{1}$ We have visited primary care group cancer leads and individual general practitioners to discuss the guidance and received no such negative feedback. Rather, doctors request simple practical guidance, not textbooks, and wish to know how it will relate to local services and whether it can be backed up by workshop teaching around case examples. However, the management of patients not meeting the guidance, but who are anxious or need referral, must be clarified to avoid overloading services.

Sikora is right that guidance sent out on its own may be binned. The key to local implementation is full discussion of shared guidelines, followed by relevant education. Now is the time to plan this and to earmark resources to assess the effect. "Access to a uniformly high quality of care" demanded by Calman-Hine must surely be equal in time as well as place.

Elizabeth Davies specialist registrar in public health East Sussex Health Authority, Epsom KT19 8PH Elizabeth.Davies@esurrey_ha.sthames.nhs.uk

Beverley van der Molen colorectal project facilitator Department of Public Health, Merton, Sutton and Wandsworth Health Authority, Mitcham CR4 4TP beverley.vandermolen@mswha.sthames.nhs.uk

Competing interest: Dr Davies was a member of the Department of Health guideline subgroup for brain cancer.

1 Department of Health. Referral guidelines for suspected cancer. London: DoH, 2000.

2 Sikora K. New guidelines for urgent referral of patients with cancer are a waste of energy. BMJ 2000;320:59. (1 January.)

3 Expert Advisory Group. A framework for commissioning cancer services. London: Department of Health, 1995.

4 Cancer Guidance Sub-group of the Clinical Outcome Group. Improving outcomes for colorectal cancer. London: NHS Executive, 1998.

5 Getting evidence into practice. Effective Health Care 1999; 5(1). (February 1999.)

\section{bmj.com}

\section{Rapid responses}

Correspondence submitted electronically

is available on our website 